\title{
Entropy Generation in Steady Laminar Boundary Layers with Pressure Gradients
}

\author{
Donald M. McEligot ${ }^{1,2, *}$ and Edmond J. Walsh ${ }^{3}$
}

1 Mechanical Engineering Department, University of Idaho, Idaho Falls, ID 83402, USA

2 Institut für Kernenergetik und Energiesysteme (IKE), Universität Stuttgart, Pfaffenwaldring 31, D-70569 Stuttgart, Germany

3 Osney Thermo-fluids Laboratory, Department of Engineering Science, University of Oxford, Osney Mead, Oxford OX2 0ES, UK; E-Mail: Edmond.Walsh@bnc.ox.ac.uk

* Author to whom correspondence should be addressed; E-Mail: Donald.McEligot@ike.uni-stuttgart.de; Tel.: +49-711-685-62138; Fax: +49-711-685-62010.

Received: 16 April 2014; in revised form: 3 July 2014 / Accepted: 7 July 2014 /

Published: 10 July 2014

In an earlier paper in Entropy [1] we hypothesized that the entropy generation rate is the driving force for boundary layer transition from laminar to turbulent flow. Subsequently, with our colleagues we have examined the prediction of entropy generation during such transitions [2,3]. We found that reasonable predictions for engineering purposes could be obtained for flows with negligible streamwise pressure gradients by adapting the linear combination model of Emmons [4]. A question then arises - will the Emmons approach be useful for boundary layer transition with significant streamwise pressure gradients as by Nolan and Zaki [5]. In our implementation the intermittency is calculated by comparison to skin friction correlations for laminar and turbulent boundary layers and is then applied with comparable correlations for the energy dissipation coefficient (i.e., non-dimensional integral entropy generation rate). In the case of negligible pressure gradients the Blasius theory provides the necessary laminar correlations.

How can one conveniently predict $C_{f}\{x\}$ and $C_{d}\{x\}$ for pure laminar boundary layers with pressure gradients? (The nomenclature we use is defined by Walsh et al. [3].) One approach would be a full computational fluid dynamics (CFD) calculation with the turbulence model suppressed. An alternate approach is to employ the Thwaites integral technique [6,7] which can be programmed on a simple spread sheet. Then, if the local freestream velocity can be approximated by a power law, $\mathrm{U}_{\infty}\{\mathrm{x}\} \sim \mathrm{x}^{\mathrm{m}}$, the correlations to be used in the Thwaites approach can be derived from Falkner-Skan solutions $[7,8]$. 
However, Thwaites did not provide a table nor a correlation for entropy generation and his table/correlations do not directly represent Falkner-Skan flows. Accordingly, our current objective is to alert readers to a new correlation for entropy generation and to improved correlations of the momentum equation function and skin friction for Falkner-Skan flows. These correlations can then be used with the Thwaites approach when appropriate.

The flow considered is laminar, steady, unheated, incompressible and two-dimensional. Fluid properties are idealized as constant and freestream turbulence is considered negligible. For a given exponent $\mathrm{m}$, the Falkner-Skan equation can be solved in a variety of ways [7,9] and for a few values they are tabulated [10-12] in terms of $\beta=2 \mathrm{~m} /(1+\mathrm{m})$. However, for the present comment we employed an Excel spread sheet kindly provided by Prof. Frank M. White for tabulations of $\mathrm{f}\{\eta\}$, $\mathrm{f}^{\prime}\{\eta\}$, $\mathrm{f} "\{\eta\}$ and $\mathrm{f} " '\{\eta\}$ plus resulting non-dimensional integral parameters. We extended this spreadsheet to obtain non-dimensional values of the pointwise entropy generation rate $S^{\prime \prime \prime}\{\eta\}$ and integral parameters, such as $\mathrm{S}^{\prime \prime}\{\infty\}$, energy dissipation coefficients and shape factors. For a pure laminar flow S"' may be derived from the viscous dissipation function $\Phi$ which evolves in the derivation of the partial differential energy equation. Under boundary layer approximations in pure laminar flows. the pointwise entropy generation rate may be calculated in wall coordinates $\left(\mathrm{U}^{+}=\mathrm{U} / \mathrm{u}_{\tau}\right.$ and $\left.\mathrm{y}^{+}=\mathrm{y} \mathrm{u}_{\tau} / \mathrm{v}\right)$ as:

$$
\left(\mathrm{S}^{\prime \prime \prime}\right)^{+} \approx\left(\partial \mathrm{U}^{+} / \partial \mathrm{y}^{+}\right)^{2}
$$

where $\left(\mathrm{S}^{\prime \prime \prime}\right)^{+}$is $\left(\mathrm{T} v \mathrm{~S}^{\prime \prime \prime}\right) /\left(\rho \mathrm{u}_{\tau}^{4}\right)$. The maximum value of $\mathrm{S}^{\prime \prime}$ is at the wall for negligible and favorable pressure gradients. For a laminar boundary layer with streamwise pressure gradients as considered here, $\left(\mathrm{S}^{\prime \prime \prime}\right)^{+}=[\mathrm{f} "\{\eta, \beta\} / \mathrm{f} "\{0, \beta\}]^{2}$. While the rate of work done by viscous stresses is zero at the wall under the no-slip condition, the pointwise $\Phi$ (and therefore $S^{\prime \prime \prime)}$ represents the net viscous work rate or gradient of this rate of work. Consequently, $\Phi$ contains terms such as $(\partial \mathrm{U} / \partial \mathrm{y})^{2}$ which are not normally zero at the wall except at a point of separation. For adverse pressure gradients $(\beta<0)$ the peak of $\mathrm{f} "\{\eta, \beta\}$ moves away from the wall as shown by White [7] in his Figures $4-11 \mathrm{~b}$. In this case, the maximum value of $\mathrm{S}$ "' therefore appears away from the wall.

For the Thwaites approach [6], one can write the integral momentum equation as:

$$
\mathrm{U}_{\infty} \mathrm{d}\left[\lambda_{\theta} /\left(\mathrm{dU} \mathrm{U}_{\infty} / \mathrm{dx}\right)\right] / \mathrm{dx}=2\left[0.5 \mathrm{C}_{\mathrm{f}} \mathrm{Re}_{\theta}-\lambda_{\theta}\left(2+\mathrm{H}_{12}\right)\right]=\mathrm{F}\left\{\lambda_{\theta}\right\}
$$

where the quantity $\lambda_{\theta}=\left(\theta^{2} / v\right) \mathrm{d} \mathrm{U}_{\infty} / \mathrm{dx}$ can be considered to be an acceleration (or pressure gradient) parameter. To perform the integration, one can correlate the function $\mathrm{F}\left\{\lambda_{\theta}\right\}$ as:

$$
\mathrm{F}\{\lambda\} \approx 0.441048-5.30934 \lambda_{\theta}
$$

For $-0.198740 \leq \beta \leq 2$, agreement with the calculated values is within $+/-0.02$ (since $F\left\{\lambda_{\theta}\right\}$ passes through zero, percentage comparisons are not useful). For predicting $\mathrm{C}_{\mathrm{f}}\{\mathrm{x}\}$ Thwaites interpolated from a table of values; however, a correlation (as by White [7]) is more convenient for design. Our calculations can be represented as:

$$
\mathrm{C}_{\mathrm{f}} \operatorname{Re}_{\theta} \approx 2.1347\left(\lambda_{\theta}-\lambda_{\text {sep }}\right)^{0.58706}
$$

where $\lambda_{\text {sep }} \approx-0.068143$ is the value at separation. Agreement is within 1.6 per cent for $-0.18 \leq \beta \leq 2$.

From our results, Figure 1 provides graphs of $F\left\{\lambda_{\theta}\right\}$ as well as $C_{f} \operatorname{Re}_{\theta}$. The circles are the individual calculated values. These correlations (solid lines) are compared to the recommendations of Thwaites [6] 
and White [7] (dashed lines). For these Falkner-Skan flows our agreement is generally better. Thwaites discussed flows with a stagnation region, like an airfoil leading edge, in terms of the Falkner-Skan solution for $U_{\infty}=0(m=\beta=1 \rightarrow F\{\lambda\}=0)$; however, our correlation for $F\{\lambda\}$ meets his criteria better than his correlation does (see Figure 1a).

Figure 1. (a) Effect of streamwise pressure gradients on integral momentum equation function, $\mathrm{F}\left\{\lambda_{\theta}\right\}$. (b) Effect of streamwise pressure gradient on skin friction coefficient. (c) Effect of streamwise pressure gradient on energy dissipation coefficient $\mathrm{C}_{\mathrm{d}}$ and present correlation for fluids design engineers. Circles $=$ present calculations, solid line $=$ present correlation.

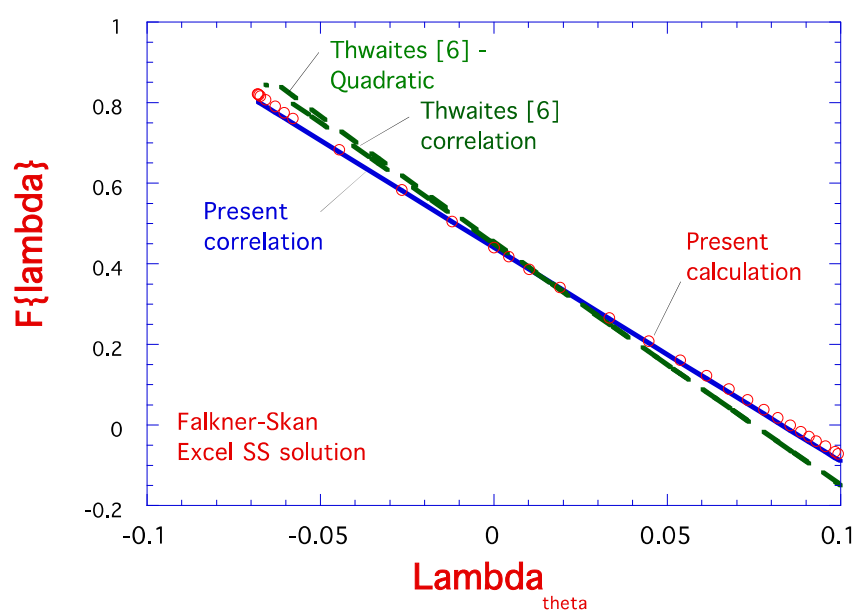

(a)

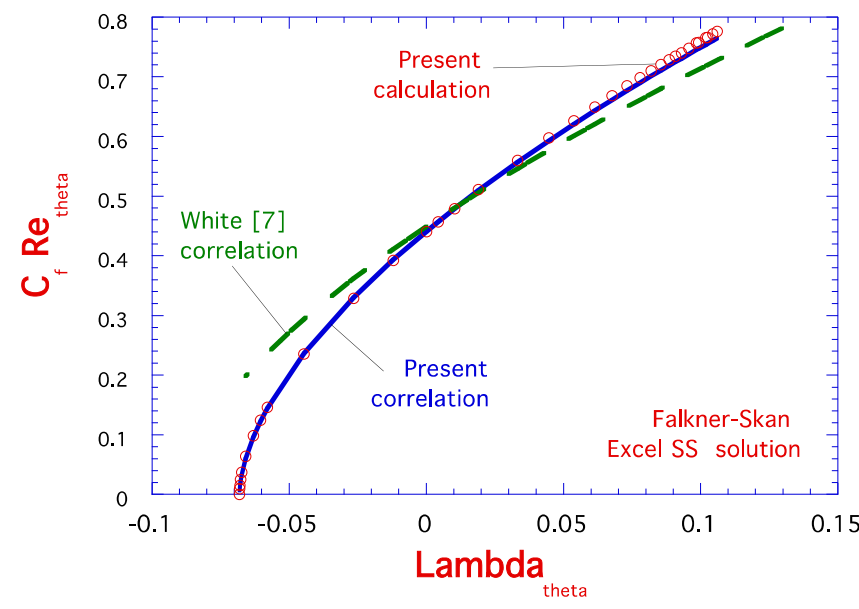

(b)

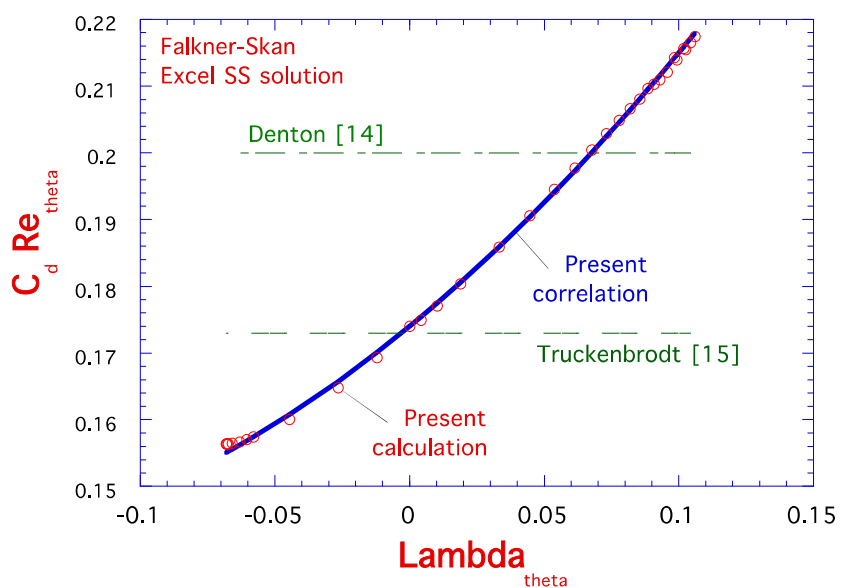

(c)

For design the entropy generation rate per unit of wall surface area $S^{\prime \prime}\{x\}$ is a key quantity for minimizing thermodynamic losses; it represents the lost work integrated across the boundary layer at a given streamwise location $\mathrm{x}$. In the present two-dimensional case further integration in the streamwise direction will provide the overall entropy generation rate for the surface. In terms of freesteam velocity, $\mathrm{U}_{\infty}$, the integral entropy generation rate $\mathrm{S}^{\prime \prime}\{\mathrm{x}\}$ may be written as a local energy dissipation coefficient $\mathrm{C}_{\mathrm{d}}$ following Schlichting [13] and Denton [14] as:

$$
\mathrm{C}_{\mathrm{d}}=\left(\mathrm{T} \mathrm{S}^{\prime \prime} /\left(\rho \mathrm{U}_{\infty}^{3}\right)\right)=\left(\mathrm{S}^{\prime \prime}\{\delta\}\right)+\left(\mathrm{C}_{\mathrm{f}} / 2\right)^{3 / 2}
$$


This dissipation coefficient is often used in design so we will present these results as $C_{d} R_{\theta}$ which has a constant value for any specific value of $\beta$ (or $\lambda_{\theta}$ ). The present results for $C_{d}$ may be correlated reasonably well with a quadratic relation:

$$
\mathrm{C}_{\mathrm{d}} \operatorname{Re}_{\theta} \approx 0.17399+0.3315 \lambda_{\theta}+0.7881 \lambda_{\theta}^{2}
$$

This correlation appears as the solid line in Figure 1c. Our calculated values are shown as circles. Over the range $-0.195<\beta<2.0$ agreement is within about 0.6 per cent. Also plotted are the constant values recommended by Truckenbrodt [15] (citing Walz [16]), Denton and Cumpsty [17], Denton [14] and others; the one by Denton agrees at $\lambda_{\theta} \approx 0.07$, a substantial favorable pressure gradient. However, one sees the variation is about forty per cent for the range of pressure gradients considered here.

\section{Conclusions}

To benefit fluid design engineer skin friction and integral entropy generation rates have been correlated as functions of the acceleration parameter $\lambda_{\theta}$. For flows that can be locally approximated as comparable to Falkner-Skan flows ("local similarity"), the correlations should provide better predictions than the Thwaites correlations of $\mathrm{F}\{\lambda\}$ and his tabular values of $\mathrm{C}_{\mathrm{f}} \mathrm{Re}_{\theta}$. And a new correlation for energy dissipation coefficient $C_{d}$ is provided; it may be applied either with the Thwaites approach [6,7] or with our improved correlations of $F\{\lambda\}$ and $C_{f} \operatorname{Re}_{\theta}$. Thus, for flows with gradually-varying streamwise pressure gradients, one can apply the Thwaites approach with the improved $\mathrm{F}\{\lambda\}$ correlation to predict $\operatorname{Re}_{\theta}\{\mathrm{x}\}$ and then-with the correlations $-\mathrm{C}_{\mathrm{f}}\{\mathrm{x}\}$ and $\mathrm{C}_{\mathrm{d}}\{\mathrm{x}\}$. However, at a stagnation point the boundary conditions for the Falkner-Skan solution are likely not valid, so this approach is not recommended there.

\section{Acknowledgments}

We thank Jörg Starflinger and Eckart Laurien of IKE, University of Stuttgart, for their gracious hospitality and support during the writing of this short letter. Its completion was partly supported financially by the U.S. DoE Experimental Program to Stimulate Competitive Research under Award DE-SC0004751 and by the Center for Advanced Energy Studies via U.S. Department of Energy Idaho Operations Office Contract DE-AC07-05ID14517.

\section{Conflicts of Interest}

The authors declare no conflict of interest.

\section{References}

1. Walsh, E.J.; Davies, M.R.D.; McEligot, D.M. On the use of entropy to predict boundary layer stability. Entropy 2004, 6, 375-387.

2. Nolan, K.; Walsh, E.J.; McEligot, D.M.; Volino, R.J. Predicting entropy generation rates in transitional boundary layers based on intermittency. J. Turbomach. 2007, 129, 512-517. 
3. Walsh, E.J.; McEligot, D.M.; Brandt, L.; Schlatter, P. Entropy generation in boundary layers transitioning under the influence of free stream turbulence. J. Fluids Eng. 2011, 133, 061203:1-061203:10.

4. Emmons, H.W. The laminar-turbulent transition in a boundary layer. J. Aero. Sci. 1951, 18, 490-498.

5. Nolan, K.P.; Zaki, T.A. Conditional sampling of transitional boundary layers in pressure gradients. J. Fluid Mech. 2013, 728, 306-339.

6. Thwaites, B. Approximate calculation of the laminar boundary layer. Aero. Q. 1949, 1, 245-280.

7. White, F.M. Viscous Fluid Flow, 3rd ed.; McGraw-Hill: Boston, MA, USA, 2006.

8. Falkner, V.M.; Skan, S.W. Some approximate solutions of the boundary layer equations. Philos. Mag. 1931, 12, 865-896.

9. Bararnia, H.; Ghasemi, E.; Soleimani, S.; Ghotbi, A.R.; Ganji, D.D. Solution of the Falkner-Skan wedge flow by 'HPM-Pade' method. Adv. Eng. Softw. 2012, 43, 44-52.

10. Hartree, D.R. On an equation occurring in Falkner and Skan's approximate treatment of the equations of the boundary layer. Proc. Cambridge Philos. Soc. 1937, 33, 223-239.

11. Evans, H.L. Laminar Boundary-Layer Theory; Addison-Wesley: Reading, MA, USA, 1968.

12. Walz, A. Boundary Layers of Flow and Temperature; MIT Press: Cambridge, MA, USA, 1969.

13. Schlichting, H. Boundary Layer Theory, 6th ed.; McGraw-Hill: New York, NY, USA, 1968.

14. Denton, J.D. Loss mechanisms in turbomachines. J. Turbomach. 1993, 115, 621-656.

15. Truckenbrodt, E. Ein Quadraturverfahren zur Berechnung der laminaren und turbulenten Reibungsschicht bei ebener und rotationssymmetrischer Strömung. Ing. Arch. 1952, 20, 211-228. (In German)

16. Walz, A. Anwendung des Energiesatzes von Wieghardt auf einparametrige Geschwindingkeitsprofile in laminaren Grenzschichten. Ing. Arch. 1948, 16, 243-248. (In German)

17. Denton, J.D.; Cumpsty, N.A. Loss mechanisms in turbomachines. IMechE Paper No. C260/87, 1987.

(C) 2014 by the authors; licensee MDPI, Basel, Switzerland. This article is an open access article distributed under the terms and conditions of the Creative Commons Attribution license (http://creativecommons.org/licenses/by/3.0/). 